\title{
Rock Mechanical Properties and Breakdown Pressure of High- Temperature and High-Pressure Reservoirs in the Southern Margin of Junggar Basin
}

\author{
Mingwei Kong, ${ }^{1}$ Zhaopeng Zhang $\mathbb{D}^{2},{ }^{2}$ Chunyan Zhao, ${ }^{1}$ Huasheng Chen, ${ }^{1}$ Xinfang Ma $\mathbb{D},{ }^{2}$ \\ and Yushi Zou ${ }^{2}$ \\ ${ }^{1}$ Engineering Technology Institute, PetroChina Xinjiang Oilfield Company, 834000, China \\ ${ }^{2}$ State Key Laboratory of Petroleum Resources and Prospecting, China University of Petroleum, (Beijing), 102249, China \\ Correspondence should be addressed to Xinfang Ma; maxinfang@cup.edu.cn
}

Received 18 October 2021; Revised 5 December 2021; Accepted 8 December 2021; Published 29 December 2021

Academic Editor: Qingwang Yuan

Copyright (C) 2021 Mingwei Kong et al. This is an open access article distributed under the Creative Commons Attribution License, which permits unrestricted use, distribution, and reproduction in any medium, provided the original work is properly cited.

\begin{abstract}
The mechanical properties of the high-temperature and high-pressure reservoirs in the southern margin of Junggar Basin have not been clearly understood, which correspondingly results in uncertainties when predicting the breakdown pressure. To address this issue, firstly, rock mechanical experiments under high temperature, high confining pressure, and high pore pressure were carried out. Secondly, empirical formulas related to the transformation of dynamic and static mechanical parameters in the regional strata were proposed. Finally, the existing prediction model for the formation breakdown pressure was improved by taking the wellbore seepage and thermal stress into consideration. Results show that under the reservoir condition of high temperature and high pressure, the rock sample tends to form closed shear cracks. High temperature causes thermal damages and the reduction of the compressive strength and elastic modulus, while the combined effects of high confining pressure and pore pressure enhance the compressive strength and plasticity of the rock sample simultaneously. Based on the correlation analysis, it is found that the static elastic modulus is linearly related to the dynamic value, while static Poisson's ratio is a quadratic function of the dynamic value. These fitting functions can be used to obtain the profiles of static elastic modulus and Poisson's ratio based on their dynamic values from the logging interpretation. Besides, the improved prediction model for the rock breakdown pressure can yield more accurate results indicated by the error less than $2 \%$. Therefore, the proposed breakdown pressure prediction model in this study can provide theoretical guidance in the selection of fracturing truck groups and the design of the pumping schedule for high-temperature and high-pressure reservoirs.
\end{abstract}

\section{Introduction}

Breakthroughs have been made for oil and gas exploration of tight sandstones in Sikeshu sag in the southern margin of Junggar Basin [1-3], revealing that multiple sets of highquality sandstone reservoirs exist in the lower assemblage of the southern margin [4-7]. The average reservoir depth is approximately $5800-6000 \mathrm{~m}$, and the pressure coefficient is 1.6-2.3 [8]. Thus, it is a typical high-temperature and highpressure ultradeep reservoir $[1,8]$. Based on the current theoretical understanding, under the complex conditions of high temperature, high pore pressure, and high tectonic stress in the deep reservoir, rock mechanical properties are different from those of shallow formations to some extent $[9,10]$. For instance, the rock deformation and failure modes may transit from elasticity and brittleness in shallow reservoirs to elastoplasticity and ductility in deep reservoirs [9]. Under this circumference, the rock mechanical properties of shallow formations obtained under conventional test conditions (i.e., high temperature and high pressure are not taken into account) are unable to represent the real in situ geomechanical properties in the deep reservoirs. From the perspective of petroleum engineering, the rock mechanical properties are associated with the successful implementations of drilling, completion, production, and workover operations [11]. Using inaccurate rock mechanical properties to design the drilling 
scheme may have a negative effect on the wellbore stability, probably leading to the borehole collapse during drilling [11]. Also, the predictions of breakdown pressure and fracture propagation geometry involved in designing the hydraulically fracturing scheme heavily depend on the accurate measurement of mechanical properties of target layers [12]. To effectively explore and develop oil and gas resources in Sikeshu sag, it is necessary to have a comprehensive knowledge of in situ geomechanical properties of the ultradeep reservoirs with high temperature, high pore pressure, and high tectonic stress.

So far, a large number of studies have been carried out on the rock mechanical properties of the deep rock mass [13-21]. Zhang et al. [13] tested the variation of rock mechanical properties from the room temperature to high temperature $\left(600-800^{\circ} \mathrm{C}\right)$ for various rocks and found that the elastic modulus generally decreases with the increase of temperature, but the effect of temperature on the compressive strength is complex. Some experts believe that this complex effect is attributed to the deformation of rock mineral particles under the high temperature [14] and the heterogeneity of mesoscale damages [15]. Tian et al. [16] and Wan et al. [17] found that the temperature affects the rock mechanical properties in a piecewise manner, and there is a temperature threshold, above which the elastic modulus and compressive strength reduce significantly. Deng et al. [18] and Kumari et al. [19] investigated the effects of confining pressures on the mechanical properties of sandstone and granite under high temperature, respectively, and found that the rock strength typically increases with the increase of confining pressure, while the brittleness gradually decreases, and the sample failure mode transforms from the tensile failure of vertical joints and fissures under the low confining pressure to the shear failure of multiple shear bands under the high confining pressure (90-120 MPa). Zhou et al. [20] tested the mechanical properties of sandstones by considering the coupling behaviour among the temperature, confining pressure, and pore pressure and found that under the constant confining pressure, the rock strength and elastic modulus decrease with the increase of pore pressure. Pan et al. [21] further pointed out that as the pore pressure in carbonate rock increases, the cohesion increases and the internal friction angle decreases. According to previous studies mentioned above, the rock mechanical properties of deep reservoirs are comprehensively influenced by the coupling among the temperature, tectonic stress, and pore pressure. To reflect the in situ geomechanical properties of deep formations, none of those three factors can be neglected while conducting rock mechanical tests.

In situ rock mechanical properties can be used to evaluate the breakdown pressure of reservoirs, which is a key parameter for in situ stress assessment and hydraulic fracturing design. For exploratory vertical wells in targeted blocks of the southern margin, the hydraulic fracturing technique is usually utilized for the formation testing and the breakdown pressure should be assessed in advance for the selection of fracturing truck groups and the design of the pumping schedule. For the open-hole completion, the stress distribution at the wellbore is generally regarded as a result of the superposition of the wellbore internal pressure, in situ stress, and additional stress induced by the fracturing fluid filtration [22]. The rock will be fractured as the stress distribution meets a certain failure criterion. For formations at shallower depths, the linear failure criterion based on the Mohr-Coulomb model is mostly used [23], but this model is too simplified to accurately predict the breakdown pressure in the deep and complex environments [24]. HubbertWillis (H-W) formula [25] and Haimson-Fairhurst (H-F) formula [26] are prediction models based on the tensile failure criterion, which can estimate the upper and lower limits of the formation breakdown pressure, respectively. Different from the $\mathrm{H}-\mathrm{W}$ model, the $\mathrm{H}-\mathrm{F}$ model considers the poroelastic effect by assuming that the rock is permeable and fluid flows through the rock mass once injected into the wellbore [24]. On these foundations, Eaton [27], Stephen [28], Anderson et al. [29], and Huang [30] successively put forward calculation methods of the breakdown pressure, which are suitable for the field application. Ito and Hayashi [31] assumed that the fracture is initiated inside the rock instead of on the borehole wall and further proposed the point stress failure criterion based on the fracture characteristic length and gave a reasonable explanation to the influences of the borehole size and pressurization rate on the breakdown pressure. Due to the difference in stress distribution around the wellbore between the perforated completion and openhole completion, breakdown pressure prediction models for the perforation completion were proposed, in which the perforation is taken as a cylinder orthogonal to the wellbore [22]. Considering the influences of the induced stress and natural fractures, Guo et al. [32] proposed a model for predicting the stress distribution on the surface of perforation channels in a horizontal well. Based on the fracture mechanics theory, Fan et al. [33] deduced the stress intensity factor at the perforation tip and accurately predicted the breakdown pressure and fracture initiation angle. Afterward, more sophisticated combined stress and energy criteria were proposed $[34,35]$. Although some fracture mechanics-based models and combined models can give accurate predicted values, the mathematical expressions in the models are complex and numerical simulations are usually required for solutions, which is not adaptive to the field application.

This study focuses on the rock mechanical properties and breakdown pressure prediction of ultradeep reservoirs in the southern margin, Junggar Basin. Currently, in situ geomechanical properties of the targeted ultradeep reservoirs are usually dynamically examined through the logging interpretation, and there is lack of adequate and reliable laboratory static data of rock samples under high pressure and high temperature. Even though some pilot tests [36, 37] have been carried out to understand the rock mechanical characteristics under high temperature and high pressure, a holistic knowledge of the in situ geomechanical properties are still needed. Besides, most of the previous studies [13-19] took the concept of "effective stress" to set the experimental confining pressure during conducting compression tests, without the consideration of pore pressures. Some studies [20, 21] that accounted for the pore pressure adopted a limited range of $0-30 \mathrm{MPa}$, which cannot represent the actual pore pressure (e.g., over $60 \mathrm{MPa}$ ) in ultradeep reservoirs. 
Consequently, to understand the in situ geomechanical characteristics of ultradeep formations, rock mechanical tests should be performed under a similar temperature-pressure condition to that of the reservoir, with the consideration of the coupling effects of high temperature, high confining pressure, and high pore pressure. As for the breakdown pressure prediction, the conventional models (e.g., $\mathrm{H}-\mathrm{W}$ and H-F models) suitable for the field application did not incorporate the component of the thermal stress. The thermal stress is taken as the additional stress caused by the temperature change at the wellbore wall during injecting the fracturing fluid. A large temperature gradient may be caused at the wellbore wall due to the high temperature (e.g., over $150^{\circ} \mathrm{C}$ ) in ultradeep reservoirs, which may induce a comparable additional stress that cannot be ignored. Therefore, considering the effect of thermal stress, an improved prediction model is proposed in this study to reduce the deviation of the predicted value from the measured value obtain from the real-time pressure curve.

The Jurassic formations in Sikeshu sag of Junggar Basin, including Badaowan, Sangonghe, Xishanyao, Toutunhe, and Qigu formations, have great potential to explore and develop. Among them, thick Toutunhe formation shows promising hydrocarbon accumulation potential and is a key candidate for the following exploration [1]. Taking the Toutunhe formation as the research object, this paper intends to perform a series of triaxial compression tests to evaluate the in situ rock mechanical properties by considering the coupling effects of the high temperature and high pressures (i.e., including the high confining pressure and high pore pressure) of ultradeep reservors. Afterward, an existing breakdown pressure prediction model was improved to give more accurate predictions for the breakdown pressure of ultradeep reservoirs on the basis of the acquired in situ geomechanical parameters. This paper is aimed at laying a theoretical foundation for the selection of "sweet spots for fracturing" and the optimization of the pumping schedule.

\section{Materials and Methods}

2.1. Geological Overview. Four sets of source rocks (i.e., Permian, Jurassic, Cretaceous, and Paleogene rock systems) are developed in the piedmont thrust belt in the southern margin of Junggar Basin, which has rich oil and gas resources. Vertically, three sets of mudstone and gypsum mudstone caprocks (i.e., Neogene taxihe formation, Paleogene Anjihaihe formation, and Cretaceous Tugulu group) are developed, which can be divided into upper, middle, and lower reservoir-cap assemblages [1]. The Toutunhe formation of lower assemblage in the Sikeshu sag includes the thick taupe glutenite formation, which contains the interbedding of medium-coarse grained sandstone and medium-fine grained sandstone, mixed with a small amount of argillaceous medium-fine grained sandstone and sandy mudstone [38]. The reservoir depth is nearly $6200 \mathrm{~m}$, the average porosity is $15.4 \%$, the permeability is $0.3-33.9 \mathrm{mD}$, the formation pressure coefficient is 1.6-2.3, and the formation temperature is about $150^{\circ} \mathrm{C}$. Thus, it is a high- temperature and high-pressure ultradeep reservoir with moderate porosity and permeability. Thin slice analysis shows that the sandstone of the Toutunhe formation belongs to the lithic sandstone or feldspathic lithic sandstone, and the mineral clastic mainly includes quartz and feldspar, with the contents of $29.33 \%-37 \%$ and $16.5 \%-27 \%$, respectively. The rock debris is mainly composed of sedimentary rocks and magmatic rocks, accounting for $17 \%-78 \%$. The content of the matrix is low, the cement is mainly calcite, and the cementation type is mostly porous cementation. In addition, the in situ stress test results show that the vertical stress of the Toutunhe formation sandstone reservoir is 174.0184.1 $\mathrm{MPa}$, the maximum horizontal principal stress is 154.5-175.8 $\mathrm{MPa}$, and the minimum horizontal principal stress is $149.4-155.6 \mathrm{MPa}$.

\subsection{Rock Mechanical Test under High Temperature and High} Pressure. The samples are collected from the Toutunhe formation in the Sikeshu sag, including the argillaceous siltstone, medium-fine grained sandstone, and glutenite. Both Brazilian splitting and triaxial compression tests under high temperature and high pressure were conducted to evaluate the mechanical properties of reservoir rocks. According to the International Society of Rock Mechanics (ISRM) standards [39], samples for Brazilian splitting tests are cylinders with a diameter of $25 \mathrm{~mm}$ and length of $13 \mathrm{~mm}$, and samples for triaxial compression tests are cylinders with a diameter of $25 \mathrm{~mm}$ and length of $50 \mathrm{~mm}$. The nonparallelism of the cylinder end face shall not exceed $0.05 \mathrm{~mm}$, and the end face also shall be perpendicular to the axis, with a maximum deviation less than $0.25^{\circ}$.

GCTS RTR-2000 triaxial rock mechanics test system was used, as shown in Figure 1. The experimental procedure for the Brazilian splitting tests can be referred to the ISRM standards [39], and the procedure for the triaxial compression test is described specifically as follows. At first, simultaneously increase the confining pressure (horizontal stress) and axial stress (vertical stress) such that the rock sample is under hydrostatic pressure. At this time, the horizontal stress is equal to axial stress. Then, the pore pressure is increased while the confining pressure and axial stress are maintained constant by the servomechanism. At the time when the pore pressure reaches the target value, the effective confining pressure is the same as the effective vertical stress. Afterward, the axial stress is increased to commence the triaxial test. During the axial compression, the confining pressure and pore pressure are kept constant by the servomechanism, meaning that effective confining pressure does not change and the effective axial stress increases with the increase of the axial stress. During the test, a curve of the deviatoric stress versus the axial strain or radial strain is recorded simultaneously. According to the working conditions of the apparatus, the experimental temperature was set to $150^{\circ} \mathrm{C}$, the confining pressure was set to $110 \mathrm{MPa}$, and the pore pressure was set to $80 \mathrm{MPa}$. In this way, both the effective confining pressure and effective vertical stress are $30 \mathrm{MPa}$ before the triaxial compression test starts. Based on the procedure described above, the deep formation condition can be realized in the laboratory. Two samples were 


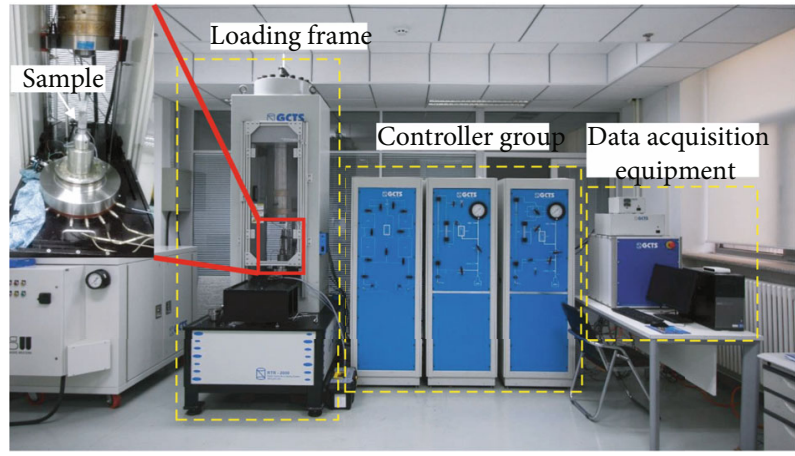

FIGURE 1: Schematic of GCTS RTR-2000 triaxial rock mechanics test system.

TABLE 1: Test scheme and results of high-temperature and high-pressure rock mechanical properties of rock samples from Toutunhe formation in the Sikeshu sag.

\begin{tabular}{|c|c|c|c|c|c|c|c|c|}
\hline No. & Lithology & $\begin{array}{l}\text { Confining } \\
\text { pressure } p_{\mathrm{c}} \\
(\mathrm{MPa})\end{array}$ & $\begin{array}{c}\text { Temperature } \\
T\left({ }^{\circ} \mathrm{C}\right)\end{array}$ & $\begin{array}{c}\text { Pore } \\
\text { pressure } p_{\mathrm{p}} \\
(\mathrm{MPa})\end{array}$ & $\begin{array}{l}\text { Tensile strength } \sigma_{\mathrm{t}} \\
(\mathrm{MPa})\end{array}$ & $\begin{array}{c}\text { Elastic } \\
\text { modulus } E \\
(\mathrm{GPa})\end{array}$ & $\begin{array}{l}\text { Poisson's } \\
\text { ratio } v\end{array}$ & $\begin{array}{c}\text { Compressive } \\
\text { strength } \sigma_{\mathrm{c}} \\
(\mathrm{MPa})\end{array}$ \\
\hline $1 \#$ & \multirow{6}{*}{$\begin{array}{l}\text { Argillaceous } \\
\text { siltstone }\end{array}$} & 110 & 150 & 80 & \multirow{7}{*}{$\begin{array}{l}6.86,8.799 .58,6.81 \\
4.33,6.466 .10,8.41\end{array}$} & $21.91,19.11$ & $0.402,0.388$ & $369.0,290.3$ \\
\hline $2 \#$ & & 90 & 150 & 60 & & $21.31,19.44$ & $0.387,0.398$ & $359.6,274.4$ \\
\hline $3 \#$ & & 60 & 150 & 30 & & $18.64,20.12$ & $0.377,0.396$ & $258.2,206.0$ \\
\hline $4 \#$ & & 30 & 150 & 0 & & $18.97,16.11$ & $0.394,0.380$ & $205.0,177.2$ \\
\hline $5 \#$ & & 110 & 25 & 80 & & $28.64,27.92$ & $0.191,0.213$ & $415.7,379.1$ \\
\hline $6 \#$ & & 30 & 25 & 0 & & $32.93,34.91$ & $0.221,0.221$ & $258.2,285.8$ \\
\hline 7\# & \multirow{6}{*}{$\begin{array}{l}\text { Medium-fine } \\
\text { grained } \\
\text { sandstone }\end{array}$} & 110 & 150 & 80 & & $26.83,24.69$ & $0.273,0.265$ & $359.0,331.2$ \\
\hline $8 \#$ & & 90 & 150 & 60 & \multirow{5}{*}{$5.27,8.476 .46,5.43$} & $28.33,21.31$ & $0.268,0.260$ & $290.2,302.4$ \\
\hline 9\# & & 60 & 150 & 30 & & $25.64,22.27$ & $0.261,0.245$ & $260.3,256.9$ \\
\hline $10 \#$ & & 30 & 150 & 0 & & $24.55,19.57$ & $0.248,0.237$ & $222.2,208.3$ \\
\hline $11 \#$ & & 110 & 25 & 80 & & $13.29,15.26$ & $0.226,0.194$ & $258.7,256.9$ \\
\hline $12 \#$ & & 30 & 25 & 0 & & $26.26,30.13$ & $0.242,0.261$ & $289.2,287.7$ \\
\hline $13 \#$ & \multirow{6}{*}{ Glutenite } & 110 & 150 & 80 & \multirow{6}{*}{$3.70,6.927 .82,5.60$} & $35.23,35.09$ & $0.232,0.220$ & $403.4,431.8$ \\
\hline $14 \#$ & & 90 & 150 & 60 & & $38.68,30.43$ & $0.238,0.217$ & $377.6,341.7$ \\
\hline $15 \#$ & & 60 & 150 & 30 & & $34.06,36.41$ & $0.231,0.206$ & $346.2,290.8$ \\
\hline $16 \#$ & & 30 & 150 & 0 & & $34.71,33.62$ & $0.217,0.194$ & $239.6,269.0$ \\
\hline $17 \#$ & & 110 & 25 & 80 & & $35.56,16.91$ & $0.259,0.184$ & $436.0,253.2$ \\
\hline $18 \#$ & & 30 & 25 & 0 & & $38.60,40.43$ & $0.338,0.191$ & $256.8,260.0$ \\
\hline
\end{tabular}

tested in each experimental group to reduce the contingency of the results. The test scheme is shown in Table 1.

2.3. Corrected Breakdown Pressure Prediction Model. In this paper, considering a two-dimensional case in which a borehole is drilled at the center of an infinite plane formation, a corrected prediction model for the formation breakdown pressure was proposed based on Huang's model [30]. The breakdown pressure model proposed by Huang improved Eaton's formula [27], as presented in

$$
p_{f}=p_{p}+\left(\frac{2 v}{1-v}-a+3 b\right)\left(\sigma_{v}-\alpha p_{p}\right)+\sigma_{t} \text {, }
$$

where $p_{\mathrm{f}}$ is the formation breakdown pressure, MPa; $p_{\mathrm{p}}$ is the initial pore pressure, $\mathrm{MPa}$; $v$ is rock Poisson's ratio; $a$ is the tectonic stress coefficient corresponding to the maxi- mum horizontal principal stress $\sigma_{\mathrm{H}} ; b$ is the tectonic stress coefficient corresponding to the minimum horizontal principal stress $\sigma_{\mathrm{h}} ; \alpha$ is the Biot elastic coefficient; $\sigma_{\mathrm{v}}$ is the formation vertical stress, $\mathrm{MPa}$; and $\sigma_{\mathrm{t}}$ is the rock tensile strength, $\mathrm{MPa}$. The above model can be decomposed into two stress terms separately caused by the in situ stress and wellbore internal pressure, which can be described as follows:

$$
\begin{aligned}
& \sigma_{\theta \theta}^{(1)}=\left(\frac{2 v}{1-v}-a+3 b\right)\left(\sigma_{v}-\alpha p_{\mathrm{p}}\right)+2 p_{\mathrm{p}}, \\
& \sigma_{\theta \theta}^{(2)}=-p_{i},
\end{aligned}
$$

where $\sigma_{\theta \theta}^{(1)}$ is the stress term caused by the in-situ stress, $\mathrm{MPa} ; \sigma_{\theta \theta}^{(2)}$ is the stress term caused by the wellbore internal pressure, $\mathrm{MPa}$; and $p_{i}$ is the fluid pressure in the wellbore, 
MPa. Equation (1) ignores the influence of the fluid infiltration into the rock stratum. Thus, two additional stresses, which are caused by the seepage effect of fracturing fluid at the wellbore wall and the temperature variation around the borehole, are not considered. However, the influences of the above two additional stresses cannot be ignored in the high-temperature and high-pressure ultradeep reservoir. Based on the theoretical analysis by Haimson and Fairhurs [26], the circumferential additional stress caused by the seepage effect of fracturing fluid is expressed by

$$
\sigma_{\theta \theta}^{(3)}=-\frac{\alpha(1-2 v)}{1-v}\left[\frac{1}{r^{2}} \int_{r_{w}}^{r} p_{n}(r) r d r-p_{n}(r)\right]
$$

where $\sigma_{\theta \theta}^{(3)}$ is the circumferential additional stress caused by the seepage effect of fracturing fluid, $\mathrm{MPa} ; r$ is the distance from the center of the wellbore, $\mathrm{m} ; r_{\mathrm{w}}$ is the wellbore radius, $\mathrm{m}$; and $p_{\mathrm{n}}(r)$ is the formation net pressure at radius $r$ , $p_{\mathrm{n}}(r)=p(r)-p_{\mathrm{p}}$, MPa. Assuming that the formation net pressure at the wellbore wall is $p_{\mathrm{n}}\left(r_{\mathrm{w}}\right)=p_{\mathrm{w}}-p_{\mathrm{p}}$, the circum- ferential additional stress caused by the seepage effect of fracturing fluid at the wellbore can be presented as follows:

$$
\sigma_{\theta \theta}^{(3)}=\frac{\alpha(1-2 v)}{1-v}\left(p_{\mathrm{w}}-\mathrm{p}_{\mathrm{p}}\right)
$$

Li et al. [40] adopted Equation (6) to represent the influence of the temperature variation at the wellbore wall on breakdown pressure. This paper stipulates that the compressive stress is positive and the tensile stress is negative.

$$
\sigma_{\theta \theta}^{(4)}=-\frac{E \alpha_{m}}{3(1-v)}\left(T_{0}-T_{\mathrm{w}}\right)
$$

where $\sigma_{\theta \theta}^{(4)}$ is the additional stress caused by the temperature variation at the wellbore wall, $\mathrm{Pa}, E$ is the rock elastic modulus, $\mathrm{MPa} ; \alpha_{\mathrm{m}}$ is the rock thermal expansion coefficient, ${ }^{\circ} \mathrm{C}^{-1}$; $T_{\mathrm{w}}$ is the fracturing fluid temperature, ${ }^{\circ} \mathrm{C}$; and $T_{\mathrm{w}}$ is the initial formation temperature, ${ }^{\circ} \mathrm{C}$. By summing up Equations (2), (3), (5), and (6) and adopting the maximum tensile stress criterion, we can obtain a corrected formation breakdown pressure prediction model, as shown in Equation (7)

$$
p_{f}=\frac{((2 v /(1-v))-a+3 b)\left(\sigma_{v}-\alpha p_{p}\right)+(2-\alpha(1-2 v) /(1-v)) p_{p}-\left(\left(E \alpha_{m} \Delta T\right) E \alpha_{m} \Delta T /(3(1-v)) 3(1-v)\right)+\sigma_{t}}{1-\alpha((1-2 v) 1-2 v /(1-v) 1-v)}
$$

where the elastic modulus $E$ and Poisson's ratio $v$ in Equation (7) are replaced by the empirical formula for the transformation between the dynamic and static mechanical parameters; then, the formation breakdown pressure can be predicted according to the logging and geological data.

\section{Results and Discussions}

\subsection{Rock Mechanical Properties under High Temperature and High Pressure}

3.1.1. Measured Values of Rock Mechanical Parameters. The results in Table 1 show that the average tensile strength of argillaceous siltstone, medium-fine grained sandstone, and glutenite are $7.17 \pm 1.58 \mathrm{MPa}, 6.41 \pm 1.28 \mathrm{MPa}$, and $6.01 \pm$ $1.55 \mathrm{MPa}$, respectively. In general, the tensile strength of argillaceous siltstone is larger than that of medium-fine grained sandstone and glutenite. In the deep formation condition, i.e., the confining pressure $p_{c}$ is $110 \mathrm{MPa}$, temperature $T$ is $150^{\circ} \mathrm{C}$, and pore pressure $p_{p}$ is $80 \mathrm{MPa}$; the average elastic modulus, Poisson's ratio, and compressive strength of argillaceous siltstone are $20.51 \mathrm{GPa}, 0.395$, and 329.7 MPa, respectively; the average elastic modulus, Poisson's ratio, and compressive strength of medium-fine grained sandstone are $25.76 \mathrm{GPa}, 0.269$, and $345.1 \mathrm{MPa}$, respectively; and the average elastic modulus, Poisson's ratio, and compressive strength of glutenite are $35.16 \mathrm{GPa}, 0.226$, and $417.6 \mathrm{MPa}$, respectively. The aforementioned results reveal that the mechanical properties of various lithologic strata are significantly different under high temperature and high pressure. Specifically, the elastic modulus and compressive strength of argillaceous siltstone are the lowest, followed by the medium-fine grained sandstone and glutenite. However, Poisson's ratio of argillaceous siltstone is the highest, while glutenite has the lowest one, with that of medium-fine sandstone falling in between.

3.1.2. Rock Deformation Characteristics and Failure Modes. By comparing the whole stress-strain curves (see Figure 2) and failure modes (see Figure 3) of samples of different lithologies under varying temperatures and pressures, it was found that under the conventional condition (i.e., $p_{c}$ is $30 \mathrm{MPa}, T$ is $25^{\circ} \mathrm{C}$, and $p_{\mathrm{p}}$ is $0 \mathrm{MPa}$ ), the deviatoric stress of argillaceous siltstone and medium-fine sandstone dropped by $57.4 \%$ and $81.1 \%$, respectively, after passing the peak, and the macroscopic shear fractures can be seen on the sample surface, indicating shearing brittle failures. However, the deviatoric stress of glutenite gradually decreased after passing the peak, and closed tensile cracks can be seen on the local surface of the sample, presenting low brittleness.

Keeping the effective confining pressure $(30 \mathrm{MPa})$ constant and only introducing the high pressure (i.e., $p_{c}$ is $110 \mathrm{MPa}, T$ is $25^{\circ} \mathrm{C}$, and $p_{\mathrm{p}}$ is $80 \mathrm{MPa}$ ), the peak stress and peak strain of the stress-strain curve and the compressive 


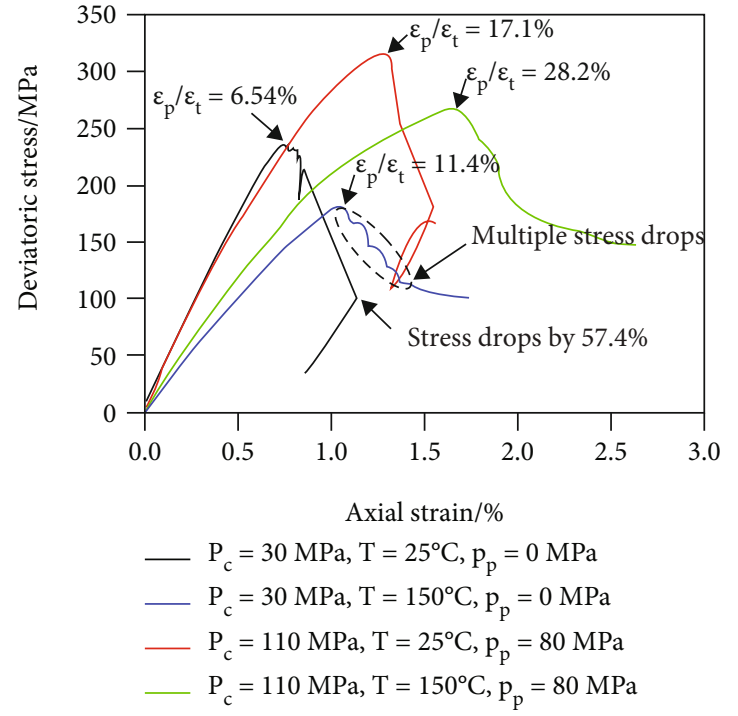

(a)

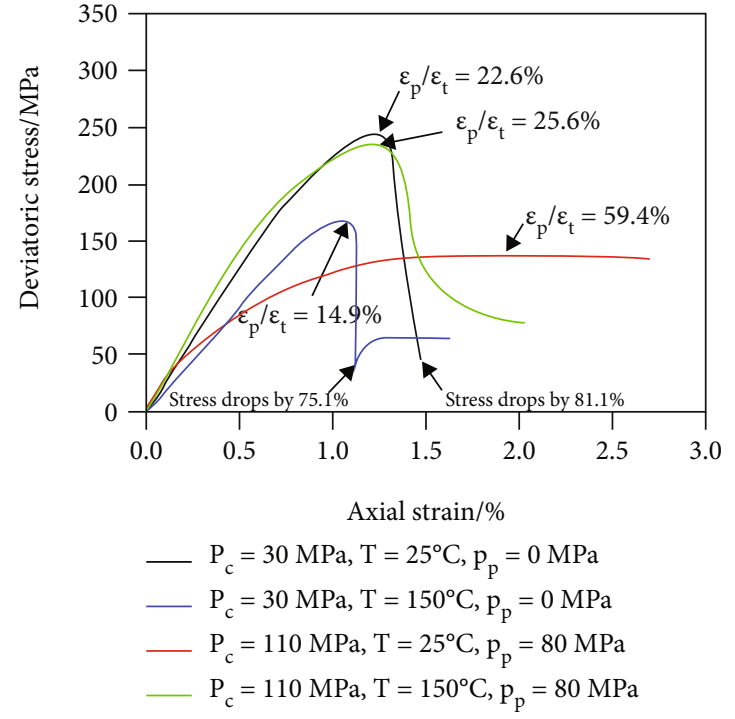

(b)

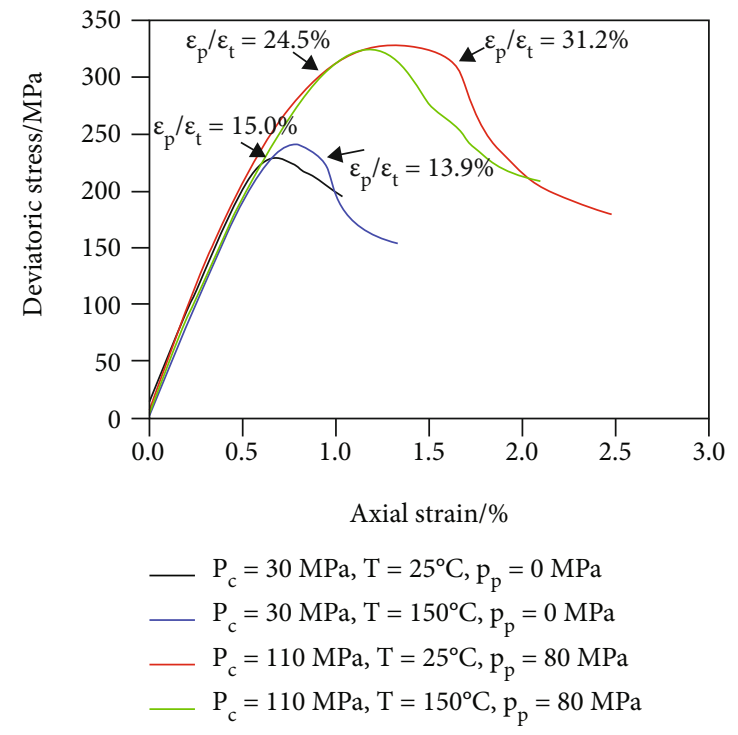

(c)

FIgURE 2: Whole stress-strain curves of samples with different lithologies under high temperature and high pressure. (a) Argillaceous siltstone. (b) Medium-fine grained sandstone. (c) Glutenite.

strength for argillaceous siltstone and glutenite significantly increased compared with the conventional test condition. For example, the proportion of the plastic strain $\left(\varepsilon_{\mathrm{p}} / \varepsilon_{\mathrm{t}}\right)$ for argillaceous siltstone and glutenite increased from $6.5 \%$ to $17.1 \%$ and from $15.0 \%$ to $24.5 \%$, respectively. As a result, the plastic deformation was enhanced, and closed shear cracks could be observed on the sample surface. The proportion of the plastic strain for medium-fine grained sandstone accounted for $59.4 \%$, and the curve after the peak tends to be flat, indicating the occurrence of the plastic creep; and there is no obvious crack on the sample surface. The above phenomena show that under the conditions of high confining pressure and pore pressure, the plastic deformation of rock samples tends to be enhanced, and an oblique shearing plane usually occurred for the primary failure.
Keeping the effective confining pressure $(30 \mathrm{MPa})$ constant and only introducing the high temperature (i.e., $p_{c}$ is $30 \mathrm{MPa}, T$ is $150^{\circ} \mathrm{C}$, and $p_{\mathrm{p}}$ is $0 \mathrm{MPa}$ ), the elastic modulus and compressive strength of argillaceous siltstone, medium-fine grained sandstone, and glutenite tended to decrease (see Table 1) compared with the conventional test condition. Specifically, the elastic modulus of argillaceous siltstone decreased from $33.92 \mathrm{GPa}$ to $17.54 \mathrm{GPa}$, with that of medium-fine grained sandstone decreasing from 28.20 GPa to $22.06 \mathrm{GPa}$ and that of glutenite decreasing from 39.52 GPa to $34.17 \mathrm{GPa}$. Additionally, the average compressive strength of argillaceous siltstone decreased from 272.0 $\mathrm{MPa}$ to $191.1 \mathrm{MPa}$, with that of medium-fine grained sandstone decreasing from $288.5 \mathrm{MPa}$ to $215.3 \mathrm{MPa}$ and that of glutenite slightly decreasing from $258.4 \mathrm{MPa}$ to 


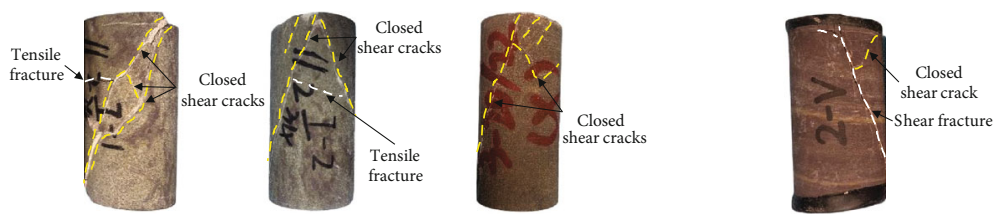

(a) Failure modes of argillaceous siltstone samples (experimental conditions from left to right are as follows: $p_{\mathrm{c}}=110 \mathrm{MPa}, T=150^{\circ} \mathrm{C}, p_{\mathrm{p}}=80 \mathrm{MPa} ; p_{\mathrm{c}}=30$ $\mathrm{MPa}, T=150^{\circ} \mathrm{C}, p_{\mathrm{p}}=0 \mathrm{MPa} ; p_{\mathrm{c}}=110 \mathrm{MPa}, T=25^{\circ} \mathrm{C}, p_{\mathrm{p}}=80 \mathrm{MPa}$; and $\left.p_{\mathrm{c}}=30 \mathrm{MPa}, T=25^{\circ} \mathrm{C}, p_{\mathrm{p}}=0 \mathrm{MPa}\right)$
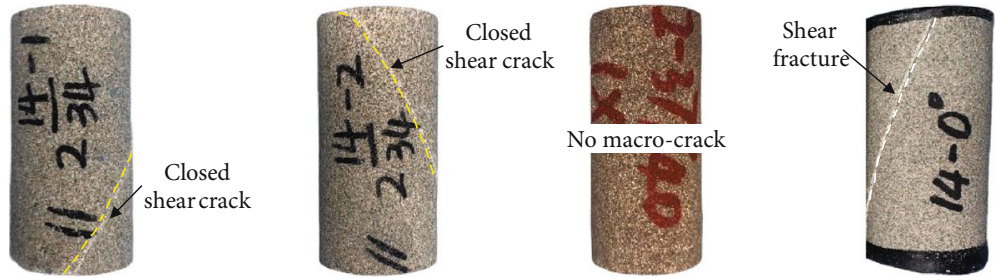

(b) Failure modes of medium-fine grained sandstone samples (experimental conditions from left to right are as follows: $p_{\mathrm{c}}=110 \mathrm{MPa}, T=150^{\circ} \mathrm{C}, p_{\mathrm{p}}=80 \mathrm{MPa}$;

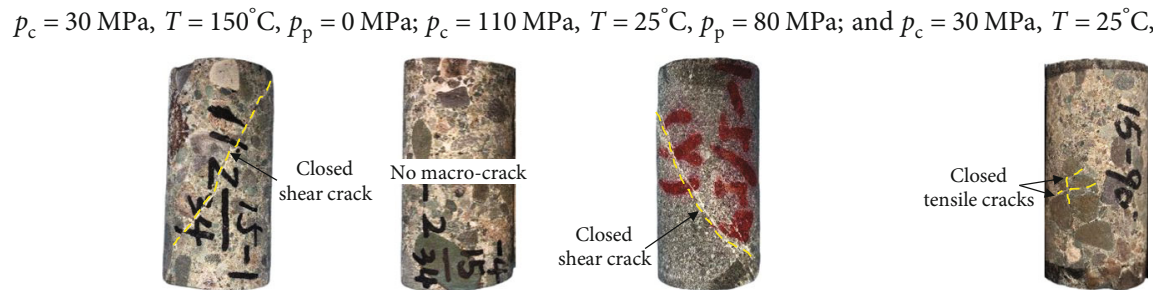

(c) Failure modes of glutenite samples (experimental conditions from left to right are as follows: $p_{\mathrm{c}}=110 \mathrm{MPa}, T=150^{\circ} \mathrm{C}, p_{\mathrm{p}}=80 \mathrm{MPa} ; p_{\mathrm{c}}=30 \mathrm{MPa}, T=150$

$$
\left.{ }^{\circ} \mathrm{C}, p_{\mathrm{p}}=0 \mathrm{MPa} ; p_{\mathrm{c}}=110 \mathrm{MPa}, T=25^{\circ} \mathrm{C}, p_{\mathrm{p}}=80 \mathrm{MPa} \text {; and } p_{\mathrm{c}}=30 \mathrm{MPa}, T=25^{\circ} \mathrm{C}, p_{\mathrm{p}}=0 \mathrm{MPa}\right)
$$

Figure 3: Illustrations of failure modes of samples with different lithologies under high temperature and high pressure.

254.3 MPa. Different from the results under the high pressure, the plastic deformation of medium-fine grained sandstone and glutenite was not enhanced, and the proportion of the plastic strain of argillaceous siltstone just increased slightly by $4.86 \%$. Besides, there were multiple stress drops after passing the peak stress in the whole stress-strain curve of argillaceous siltstone, as shown in Figure 2(c), indicating that multiple failures may occur in the sample. Consequently, multiple intersecting or parallel closed shearing cracks were formed on the sample surface. As for mediumfine grained sandstone, the deviatoric stress dropped significantly by $75.1 \%$ after passing the peak, with an oblique shearing plane formed on the sample surface, indicating a brittle failure.

Under the high temperature, the rock sample tended to be softened, which was reflected by a gradual strength weakening, and meanwhile, was accompanied by multiple failures. This is because mineral grains can expand due to the increase of temperature and there exist differences in the value of the thermal expansion coefficient among various minerals, which may cause the difference in the magnitude of the thermal strain among these minerals and further induce the generation of shearing micro-cracks $[15,16]$. Hence, the macroscopic strength of the rock sample can be weakened. Moreover, local microcracks were gradually connected to form multiple macroscopic shearing bands during loading the sample [19], which were reflected by multiple stress drops in the whole stress-strain curve. For glutenite under the high temperature, the deviatoric stress gradually decreased after passing the peak, without macrocracks on the sample surface, and in the meantime, with a slight decrease of the compressive strength. This is because glutenite contains gravels with high strengths, and the temperature of $150^{\circ} \mathrm{C}$ has not reached the thermal damage threshold of the gravel. Although the matrix of glutenite was fractured by local microcracks produced under the high temperature, the gravel still possessed the bearing capacity. Additionally, there was probably slippage between the gravel and matrix during load the glutenite sample, causing mesoscale damages along the gravel interface.

It is necessary to point out that the rock mechanical properties of deep reservoirs are determined by the coupling among the temperature, in situ stress, and pore pressure. According to the experimental results, when the effective confining pressure is constant, increasing the confining pressure or pore pressure tends to enhance the compressive strength and plastic deformation of rock samples, while the high temperature tends to soften the rock, causing the elastic modulus and compressive strength of rock samples to decrease. However, the comprehensive effect of the confining pressure, pore pressure, and temperature on rock mechanical properties is complicated. For argillaceous siltstone, the elastic modulus of the rock sample under high temperature and high pressure is lower than that under the conventional condition, while Poisson's ratio and compressive strength are larger than those under the conventional condition. For medium-fine grained sandstone, the compressive strength under high temperature and high pressure is larger than that under the conventional condition, but the elastic modulus and Poisson's ratio are similar to those 

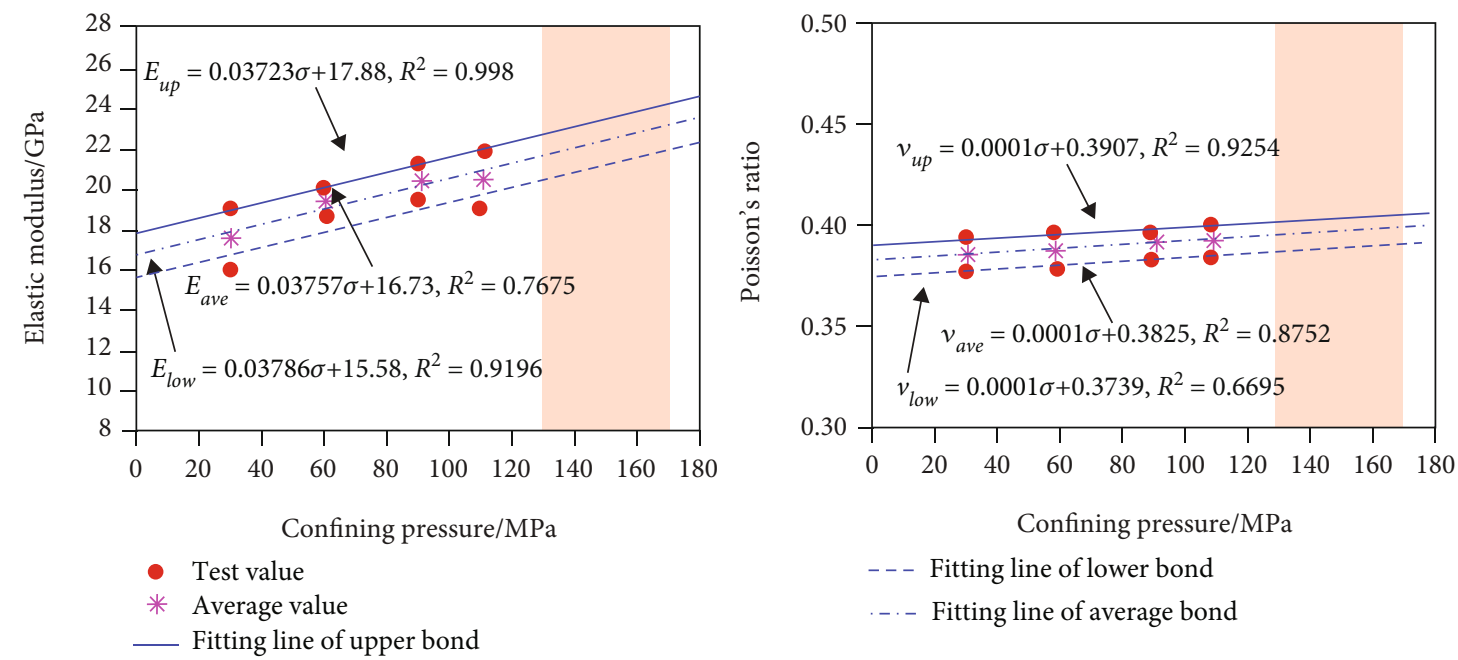

(a) Argillaceous siltstone ((A) elastic modulus and (B) Poisson's ratio)
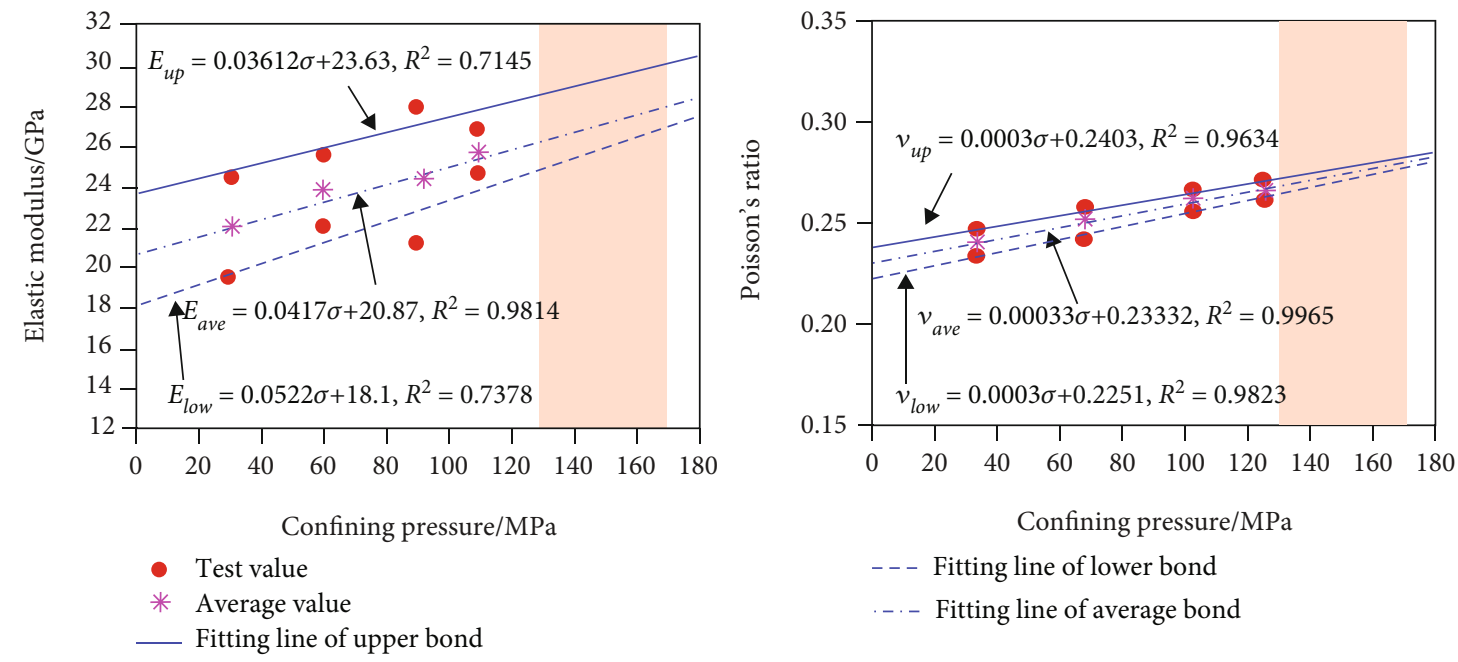

(b) Medium-fine grained sandstone ((A) elastic modulus and (B) Poisson's ratio)

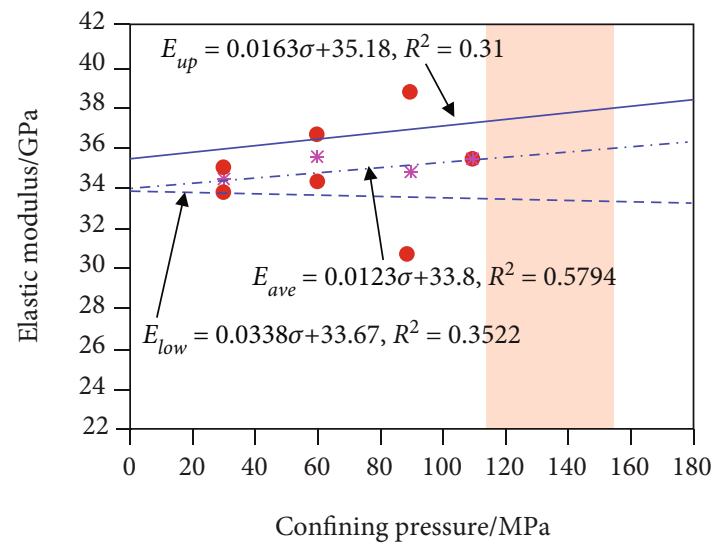

- Test value

* Average value

_ Fitting line of upper bond

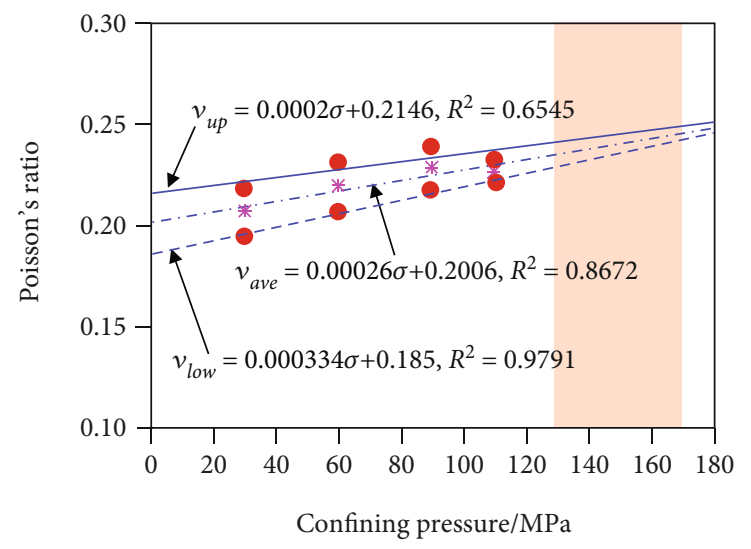

- - - Fitting line of lower bond

-..- Fitting line of average bond

(c) Glutenite ((A) elastic modulus and (B) Poisson's ratio)

FIGURE 4: Extrapolation of mechanical parameters of samples with different lithologies (the red area is the corresponding confining pressure range of the reservoir). 


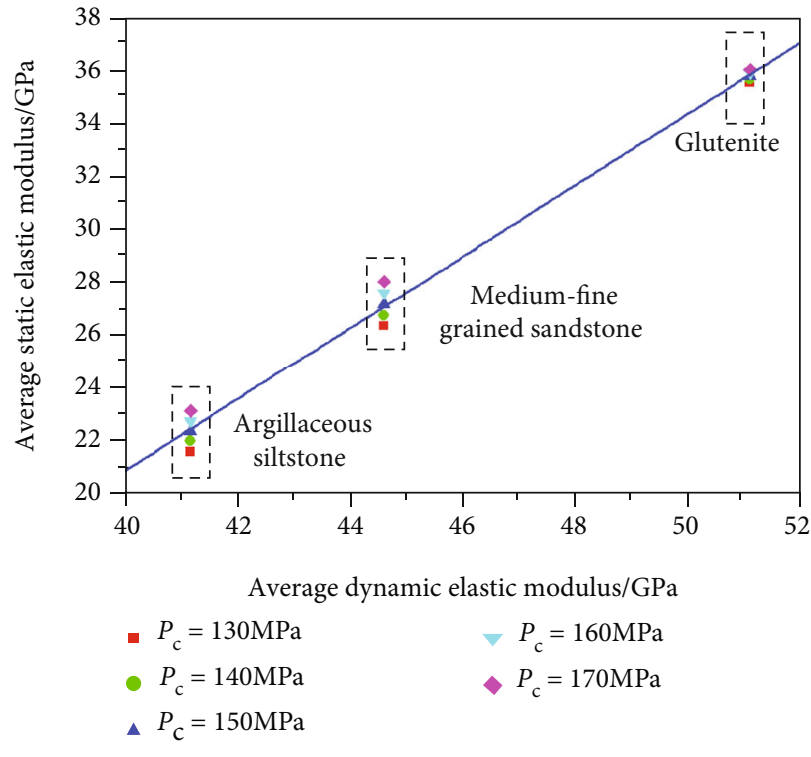

(a)

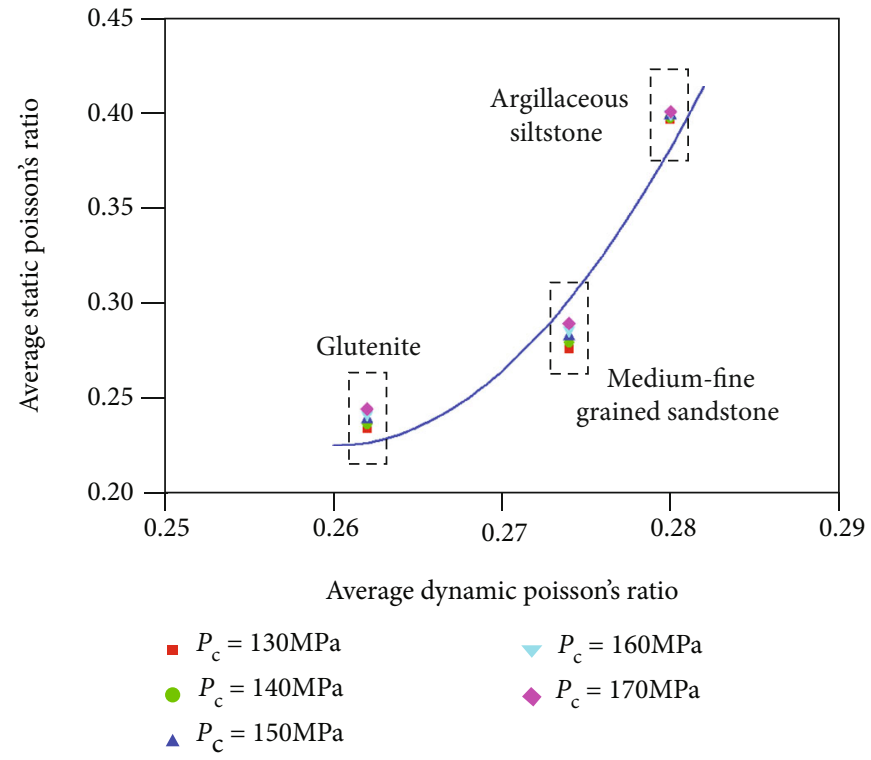

(b)

Figure 5: Dynamic and static mechanical parameter transformation. (a) Transformation for the elastic modulus. (b) Transformation for Poisson's ratio.

under the conventional condition. As for glutenite, the variation trend of the compressive strength under high temperature and high pressure is similar to that of argillaceous siltstone and medium-fine grained sandstone. Compared with glutenite sample under the conventional condition, however, the elastic modulus and Poisson's ratio under high temperature and high pressure are smaller. Apart from the lithology possibly causing the difference in mechanical properties, some studies point out that rock mechanical properties may vary in a piecewise manner under high temperature and high pressure due to a potential threshold temperature, which complicates the variation law of mechanical parameters $[13,17]$. The experimental results also show that from the conventional test condition (i.e., low confining pressure and room temperature) to the condition of the high temperature, high confining pressure, and high pore pressure, the rock failure mode tends to transit from forming shearing macro-cracks to forming shearing closed damaged cracks, and meanwhile, transit from the shearing brittle failure to the mesoscale structural damage accompanied by the enhanced plastic deformation.

3.1.3. Empirical Formula for Transformation of Dynamic and Static Mechanical Parameters. Due to the limitation of the apparatus performance, the real in situ stress condition cannot be achieved in laboratory rock mechanical tests. Because the pressure coefficient of the Toutunhe formation ranges from 1.6 to 2.3 , the corresponding formation pressure is about $100-140 \mathrm{MPa}$. Please note that the in situ stress is approximately $130-170 \mathrm{MPa}$, then, the corresponding effective confining pressure is about $30 \mathrm{MPa}$, which is the same as that adopted in the rock mechanical test. Thus, the rock mechanical parameters under 130-170 MPa confining pressure (i.e., the in situ stress condition) can be obtained by extrapolating the test results in laboratories (i.e., the results of Nos. 1 4\#, $7 \sim 10 \#$, and 13 16\#). The extrapolation results are shown in Figure 4.

It can be seen from Figure 4 that both the elastic modulus and Poisson's ratio increased approximately linearly with the increase of the confining pressure. The fitting results show that the lower bound of the elastic modulus of glutenite decreased as the confining pressure increased. This trend was caused by the abnormally low measured value under $90 \mathrm{MPa}$ confining pressure. In addition, the matching degree of the linear extrapolation correlation for the elastic modulus and Poisson's ratio of glutenite is lower than that of argillaceous siltstone and medium-fine grained sandstone. In the future, this linear extrapolation correlation needs to be further verified for glutenite. Figure 4 shows that under the reservoir condition (i.e., $130-170 \mathrm{MPa}$ confining pressure), the elastic modulus of argillaceous siltstone is 20.50 24.21 GPa and Poisson's ratio is 0.387-0.404; for mediumfine grained sandstone, the elastic modulus is 24.8929.77 GPa and Poisson's ratio is $0.273-0.279$; as for glutenite, the elastic modulus is $33.06-37.96 \mathrm{GPa}$ and Poisson's ratio is $0.228-0.249$. To facilitate the field application, empirical formulas for the transformation between dynamic mechanical parameters obtained from the logging interpretation of sampling wells and static mechanical parameters obtained from laboratory tests were established, as indicated in Figure 5. It was known from Figure 5 that the average dynamic elastic modulus of argillaceous siltstone is $41.78 \mathrm{GPa}$ and average dynamic Poisson's ratio is 0.280 ; the average dynamic elastic modulus of medium-fine grained sandstone is $44.59 \mathrm{GPa}$ and average dynamic Poisson's ratio is 0.274 ; and the average dynamic elastic modulus of glutenite is $51.09 \mathrm{GPa}$ and average dynamic Poisson's ratio is 0.262 . Comparing the dynamic mechanical parameters with the corresponding 
TABLE 2: Basic parameters of the sensitivity analysis for the corrected breakdown pressure prediction model.

\begin{tabular}{lccc}
\hline Parameters & Values & Parameters & Values \\
\hline Elastic modulus $E(\mathrm{GPa})$ & $18-40$ & Fracturing fluid temperature $T_{\mathrm{w}}\left({ }^{\circ} \mathrm{C}\right)$ & 25 \\
Poisson's ratio $v$ & $0.18-0.40$ & Initial formation temperature $T_{0}\left({ }^{\circ} \mathrm{C}\right)$ & $100-200$ \\
Vertical stress $\sigma_{\mathrm{v}}(\mathrm{MPa})$ & 160 & Rock thermal expansion coefficient $\alpha_{\mathrm{m}}\left(1 /{ }^{\circ} \mathrm{C}\right)$ & 0.00004 \\
Pore pressure $p_{\mathrm{p}}(\mathrm{MPa})$ & $100-150$ & Tectonic stress coefficient $a$ & 0.6 \\
Biot elastic coefficient & 0.8 & Tectonic stress coefficient $b$ & \\
Tensile strength $\sigma_{\mathrm{t}}(\mathrm{MPa})$ & 7 & & \\
\hline
\end{tabular}

static mechanical parameters for samples with various lithologies, it is found that there is a good linear correlation between the dynamic and static elastic modulus (as shown in Equation (8)), while the correlation between the dynamic and static Poisson's ratio can be characterized by a quadratic function (as shown in Equation (9)). These two equations can be given as follows:

$$
\begin{aligned}
& E_{s}=1.3373 E_{d}-32.62, \\
& v_{s}=384.7 v^{2}-200 v+26.22,
\end{aligned}
$$

where $E_{\mathrm{s}}$ is the static elastic modulus, GPa; $E_{\mathrm{d}}$ is the dynamic elastic modulus, GPa; $v_{s}$ is the static Poisson's ratio; and $v_{\mathrm{d}}$ is the dynamic Poisson's ratio.

\subsection{Breakdown Pressure Prediction}

3.2.1. Parametric Sensitivity Analysis. In this section, the sensitivity analysis on the rock breakdown pressure was carried out based on Equation (7). Four factors, i.e., the formation rock elastic modulus, Poisson's ratio, pore pressure, and formation temperature, were analyzed. The simulation parameters are shown in Table 2, and the simulation results of the sensitivity analysis are shown in Figure 6.

As can be seen from Figure 6(a), when the elastic modulus increases from $18 \mathrm{GPa}$ to $40 \mathrm{GPa}$, the breakdown pressure decreases by about $27.2 \%$, which is due to the additional stress caused by the wellbore temperature variation. When the temperature difference is kept constant, the larger the elastic modulus is, the higher the additional tensile stress is, and the lower the breakdown pressure is. Li et al. [40] believe that this additional stress term is sensitive to the lithology and found that the influence of the temperature variation on the breakdown pressure of hard brittle shale and limestone formations with a high elastic modulus and low Poisson's ratio was far greater than that of loose sandstone and soft mudstone with a low elastic modulus and high Poisson's ratio. According to the experimental results in this paper, the predicted average elastic moduli of argillaceous siltstone, medium-fine grained sandstone, and glutenite under the confining pressure of $160 \mathrm{MPa}$ are $22.74 \mathrm{MPa}, 27.54 \mathrm{MPa}$, and $35.78 \mathrm{MPa}$, respectively, and the corresponding breakdown pressures are $169.3 \mathrm{MPa}$, 158.8 MPa, and 140.7 MPa, respectively. The wellbore temperature variation has the greatest impact on the breakdown pressure of glutenite. Therefore, for the deep formation under the high confining pressure, the low elastic modulus and the high confining pressure amplify the influence of the additional stress term caused by the wellbore temperature variation, which cannot be ignored in the breakdown pressure prediction.

Figure 6(b) reveals that the breakdown pressure is positively correlated with Poisson's ratio. When Poisson's ratio increases from 0.18 to 0.40 , the breakdown pressure increases by about $54.7 \%$. Based on the results shown in Figure 4, when the temperature and effective confining pressure are kept constant, Poisson's ratio increases as the confining pressure increases. In this paper, Poisson's ratios of argillaceous siltstone, medium-fine grained sandstone, and glutenite under the confining pressure of $160 \mathrm{MPa}$ are estimated to be $0.399,0.286$, and 0.242 , respectively. The corresponding breakdown pressures are 214.0 MPa, 169.9 MPa, and $154.8 \mathrm{MPa}$, respectively. The larger Poisson's ratio is, the stronger the rock deformation is, which means that $\varepsilon_{\mathrm{p}} /$ $\varepsilon_{\mathrm{t}}$ increases. Under the reservoir condition adopted in this paper (i.e., $p_{\mathrm{c}}$ is $110 \mathrm{MPa}, T$ is $150^{\circ} \mathrm{C}$, and $p_{\mathrm{p}}$ is $80 \mathrm{MPa}$ ), $\varepsilon_{\mathrm{p}}$ $/ \varepsilon_{\mathrm{t}}$ of argillaceous siltstone, medium-fine grained sandstone, and glutenite are $28.2 \%, 25.6 \%$, and $24.5 \%$, respectively, which will be higher under the real reservoir condition, suggesting that the plastic deformation is stronger. Guo et al. [41], considering the elastoplastic characteristics of rocks, studied the hydraulic fracturing in a vertical well with the open-hole completion and found that the breakdown pressure of the plastic formation is higher than that of the elastic brittle formation, which is consistent with the variation trend shown in Figure 6(b). To summarize, the higher the Poisson's ratio is, the stronger the plastic deformation is, and the higher the breakdown pressure is.

It can be revealed from Figure 6(c) that the rock breakdown pressure increases with the pore pressure when keeping the other parameters constant. For example, when the pore pressure increases from $100 \mathrm{MPa}$ to $150 \mathrm{MPa}$, the breakdown pressure increases by $46.6 \%$. The contributions of the pore pressure include the wellbore internal pressure and additional stress caused by the seepage at the wellbore wall. At the same depth, the larger the pore pressure is, the higher the bottom-hole pressure is, leading to the increase of the formation net pressure $\left(p_{\mathrm{n}}\right)$ at the borehole wall. Thus, the net stress caused by the wellbore internal pressure and the additional stress caused by the seepage at the borehole wall will increase, and the formation breakdown pressure will correspondingly increase. On the other hand, when the confining pressure keeps constant, the increase of the pore pressure may lead to the decrease of the effective confining 


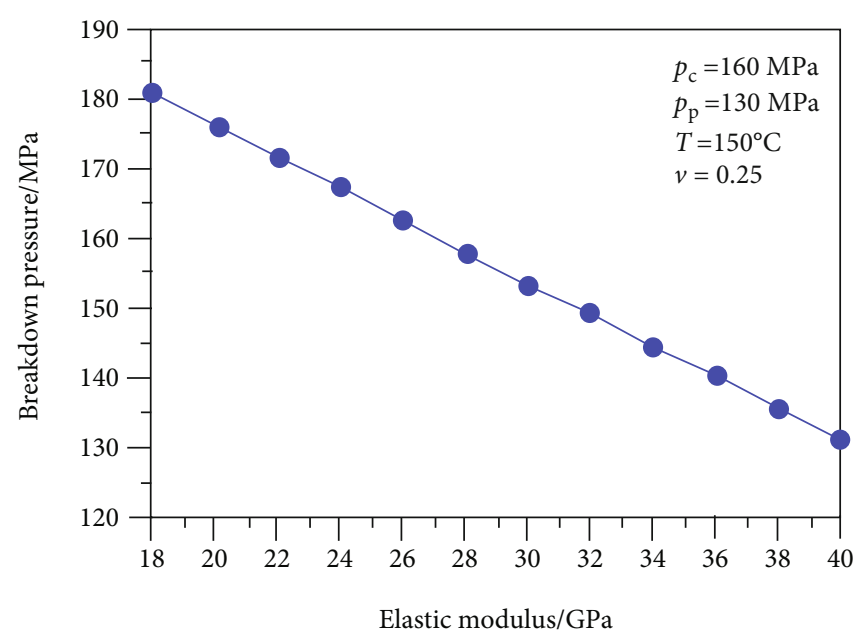

(a)

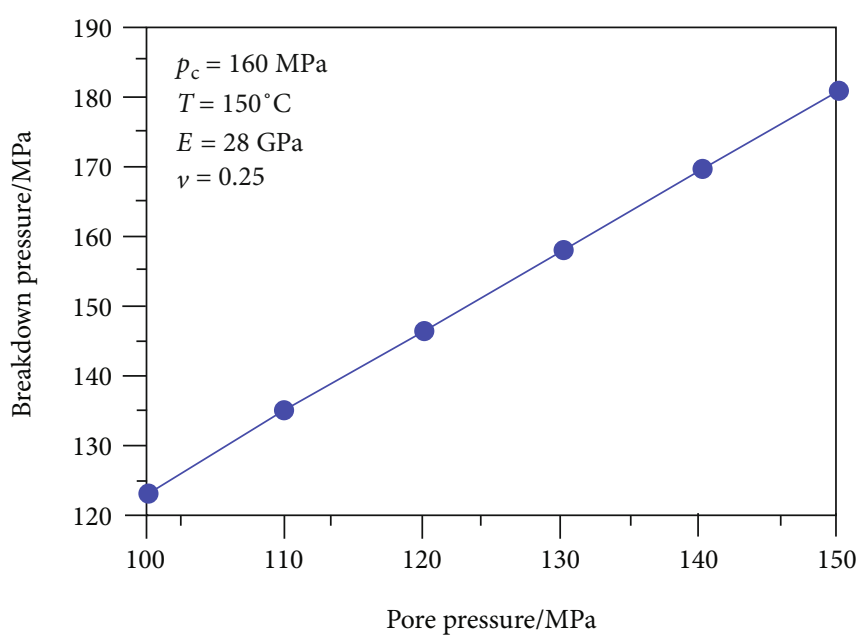

(c)

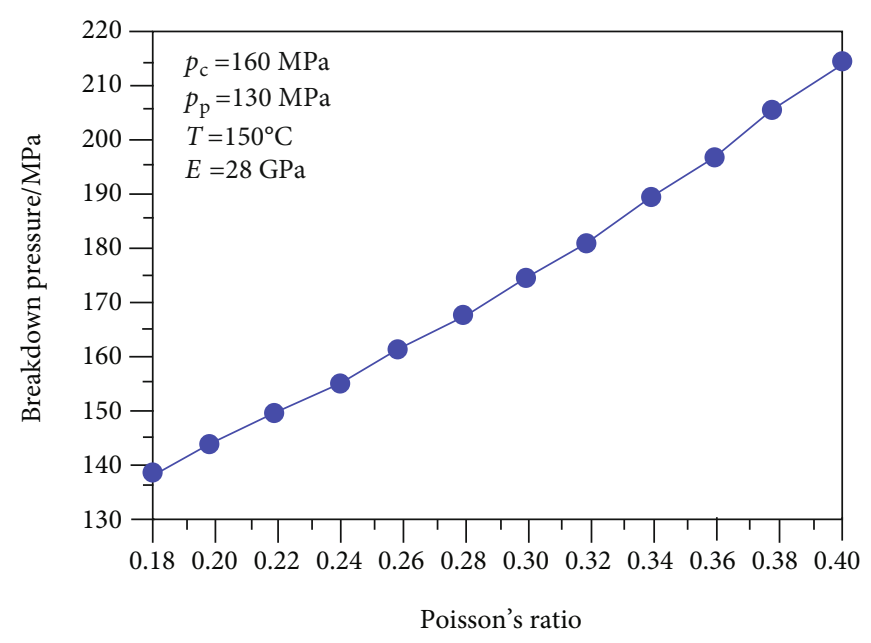

(b)

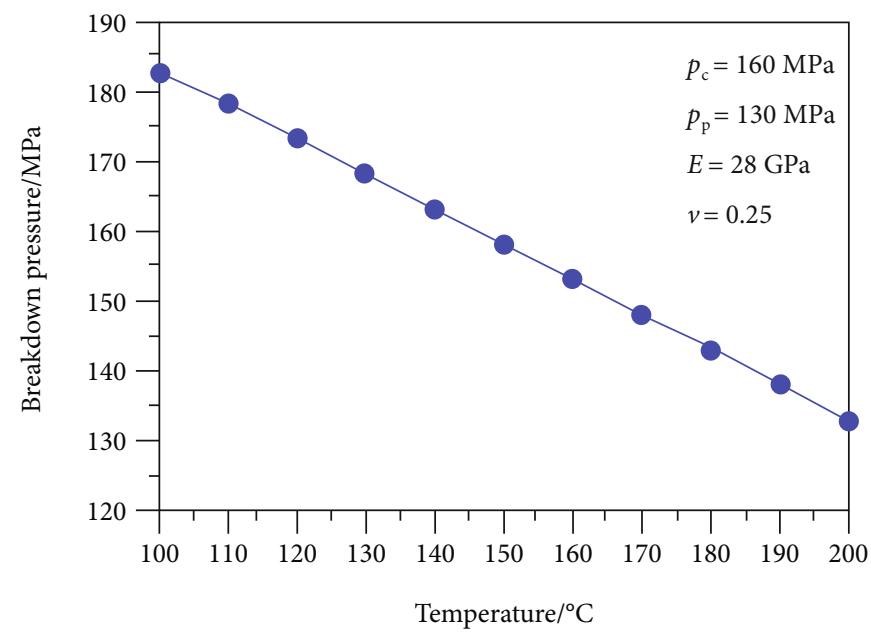

(d)

Figure 6: Parametric sensitivity analysis of the formation breakdown pressure. (a) Effect of elastic modulus. (b) Effect of Poisson's ratio. (c) Effect of pore pressure. (d) Effect of formation temperature.

pressure. Pan et al. [21] pointed out that when the effective confining pressure decreases, the elastic modulus of rocks tends to decrease, thus weakening the effect of the thermal stress caused by the wellbore temperature variation. Figure 6(d) further reflects the influence of the formation temperature variation on the rock breakdown pressure. When the other parameters kept constant, the breakdown pressure decreases with the increase of formation temperature. The injection of the fracturing fluid under the high temperature leads to a large temperature difference inside the rock, enhancing the thermal stress. At the same time, the thermal expansion coefficients of various minerals are different, which results in differences in the thermal strain among different minerals. In addition, the local thermal cracking could further reduce the formation breakdown pressure. It should be noted that the influence of the temperature variation on rock mechanical parameters is not considered in Figure 6(d). The effect of the temperature on rock mechanical properties is complex. Zhang et al. [42] pointed out that with the increase of temperature, the Poisson's ratio of rocks tends to decrease first and then increase, while the elastic modulus tends to increase first and then decrease. The changes of elastic modulus and Poisson's ratio affect the formation breakdown pressure in turn. Therefore, while considering the effect of the thermal stress, it is also necessary to comprehensively consider the influence of the temperature variation on the elastic modulus and Poisson's ratio of rocks around the wellbore.

3.2.2. Field Application. In this section, the corrected model was verified against an actual case. Well Xihu 1 is an exploration vertical well in the Xihu anticline of the Sikeshu sag, piedmont thrust belt in the southern margin of Junggar Basin. The mechanical test has been carried out for Jurassic Qigu formation, and the breakdown pressure monitored in the treatment is about $144 \mathrm{MPa}$. The well depth at the target layer is $6139.0-6160.0 \mathrm{~m}$, the temperature of the target layer is $140^{\circ} \mathrm{C}$, and the formation pressure is $116-120 \mathrm{MPa}$. Based on the logging interpretation of stimulation stage, the average dynamic elastic modulus is about $49.46 \mathrm{GPa}$, average 


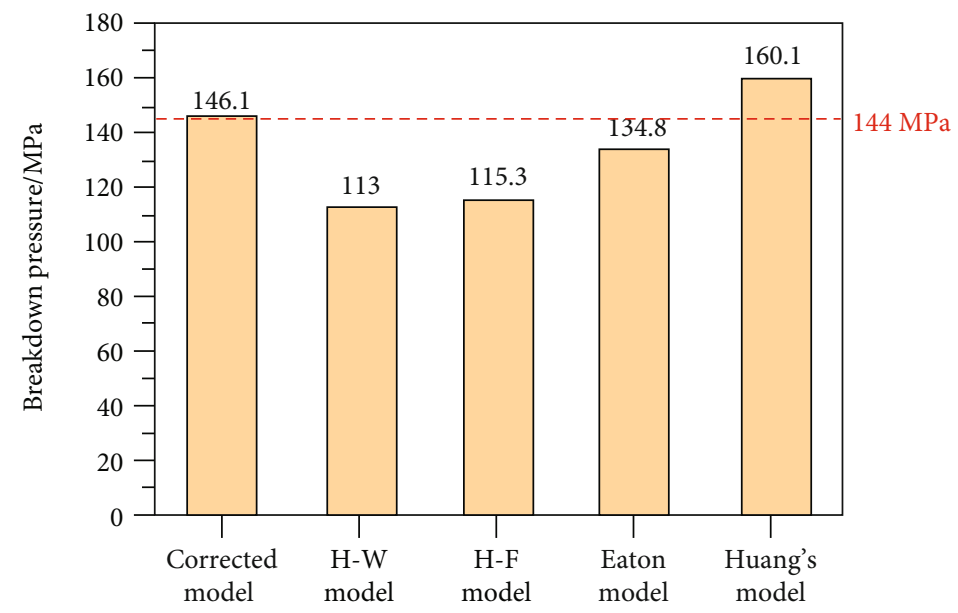

Figure 7: Prediction results of the breakdown pressure by different models.

dynamic Poisson's ratio is 0.27 , the minimum horizontal principal stress is $123-140 \mathrm{MPa}$, and the average tensile strength is $10.13 \mathrm{MPa}$. The tectonic stress coefficients corresponding to the maximum and minimum horizontal principal stresses are 0.6 and 0.11 , respectively. Other necessary parameters are consistent with those in Table 2. We adopt the proposed empirical formulas for the transformation between the dynamic and static mechanical parameters and the corrected breakdown pressure model to predict the breakdown pressure in the target formation. Meanwhile, the predicted value was comprehensively compared with those by other models such as the H-W model [25], H-F model [26], Eaton model [27], and Huang's model [30]. The prediction results are shown in Figure 7.

It can be seen from Figure 7 that the predicted values of the formation breakdown pressure given by the $\mathrm{H}-\mathrm{W}$ model and $\mathrm{H}-\mathrm{F}$ model are $113 \mathrm{MPa}$ and $115.3 \mathrm{MPa}$, respectively, which are nearly $30 \mathrm{MPa}$ lower than the measured value, with an error of about $20.8 \%$. The predicted value of the Huang's model is $160.1 \mathrm{MPa}$, which is about $16 \mathrm{MPa}$ higher than the measured value, with an error of $11.1 \%$. The predicted value from the Eaton model is $134.8 \mathrm{MPa}$, about $10 \mathrm{MPa}$ lower than the measured value, and the prediction error is about $6.4 \%$. By contrast, the predicted value from the corrected model is $146.1 \mathrm{MPa}$, which is only $2.1 \mathrm{MPa}$ higher than the measured value, with an error of $1.46 \%$. It shows that considering the seepage effect at the wellbore wall and the thermal stress will improve the prediction accuracy. The empirical formula for the transformation between dynamic and static mechanical parameters and the corrected breakdown pressure model proposed in this paper have demonstrated promising applicability.

\section{Conclusions}

Aiming at the ultradeep reservoir in Sikeshu sag on the southern margin of Junggar Basin, the evaluation of rock mechanical properties was performed under a similar temperature-pressure condition to that of the ultradeep reservoir, with the consideration of the coupling effects of high temperature, high confining pressure, and high pore pres- sure. Besides, an improved prediction model for the formation breakdown pressure was proposed by taking the wellbore seepage and thermal stress into consideration. The primary findings can be summarized as follows:

(a) While keeping the effective confining pressure constant, under high confining pressure and high pore pressure, the rock compressive strength tends to be enhanced. Meanwhile, the peak strain and proportion of plastic strain are both increased, with the plasticity also enhanced. However, high temperature is inclined to softening the rock, resulting in mesoscale thermal damages and the reduction of the compressive strength and elastic modulus. Besides, the rock failure mode tends to transit from forming shearing macroscopic fractures under the conventional mechanical condition to forming a single or multiple closed shearing cracks under high temperature and high pressure

(b) Keeping the effective confining pressure constant, the static elastic modulus and Poisson's ratio of the deep strata are approximately linearly correlated to the confining pressure. There is also a linear correlation between the static and dynamic elastic modulus, while there is a quadratic correlation between the static and dynamic Poisson's ratio. These fitting functions can be used to obtain the profiles of static elastic modulus and Poisson's ratio based on their dynamic values from the logging interpretation

(c) The thermal stress caused by the temperature variation at the wellbore wall has a great effect on the reduction of the breakdown pressure in the hard brittle deep high-temperature formation with a high elastic modulus and low Poisson's ratio. Considering the influences of the seepage at the wellbore wall and the thermal stress, the corrected breakdown pressure prediction model can give more accurate prediction results than some other classical models. The proposed model in this study can provide theoretical guidance in the selection of fracturing truck groups 
and the design of the pumping schedule for hightemperature and high-pressure reservoirs

\section{Data Availability}

The data used to support the findings of this study are available from the corresponding author upon request.

\section{Conflicts of Interest}

The authors declare that there is no conflict of interest regarding the publication of this paper.

\section{Authors' Contributions}

Conceptualization was done by M.W. and X.F. Methodology was done by Y.S. Formal analysis was performed by Z.P. and C.Y. Investigation was conducted by Z.P. and C.Y. Resources were acquired by M.W., C.Y., and H.S. Writing-original draft preparation was done by Z.P. Writing-review and editing was done by Y.S. Visualization was done by H.S. Supervision was done by X.F. Project administration was done by M.W. and X.F. All authors have read and agreed to the published version of the manuscript.

\section{Acknowledgments}

This study was supported by the National Natural Science Foundation of China (51974332).

\section{References}

[1] J. H. Du, D. M. Zhi, J. Z. Li et al., "Major breakthrough of well Gaotan 1 and exploration prospects of lower assemblage in southern margin of Junggar Basin, NW China," Petroleum Exploration and Development, vol. 46, no. 2, pp. 205-215, 2019.

[2] Y. B. Zhang, M. J. Wang, Z. L. Du, and Q. D. Yuan, "Main oil source rocks and oil-source correlation in the Sikeshu sag, the southern margin of Junggar Basin," Marine Geology Frontiers, vol. 36, no. 12, pp. 39-48, 2020

[3] D. S. Yang, L. X. Xiao, G. H. Yan, W. E. I. Lingyun, W. A. N. G. Xin, and W. A. N. G. Xinqiang, "Structural characteristics and petroleum exploration in Sikeshu sag, southern margin of Junggar Basin," Xinjiang Petroleum Geology, vol. 40, no. 2, pp. 138-144, 2019.

[4] Z. Yang, Q. Y. Li, X. F. Qi, and D. Yang, "A new possible giant hydrocarbon generated formation: the Upper Triassic source rock in Southwestern Junggar Basin, NW China," Marine and Petroleum Geology, vol. 88, pp. 575-586, 2017.

[5] D. W. Lei, J. Zhang, N. G. Chen, and B. L. Xiang, "Conditions for gas pooling in the lower assemblage in the southern margin of the Junggar Basin and the exploration prospect of large hydrocarbon fields," Natural Gas Industry, vol. 32, no. 2, pp. 16-22, 2012.

[6] L. C. Kuang, X. L. Wang, J. Zhang, and H. P. Xia, "Structural modeling of the Huoerguosi-Manasi-Tugulu thrust belt at the southern margin of the Junggar Basin and the discovery of the Mahe gas field," Natural Gas Industry, vol. 32, no. 2, pp. 11-16, 2012.
[7] X. Y. Li, Y. Shao, and T. M. Li, "Three oil-reservoir combinations in south marginal of Junggar Basin, Northwest China," Petroleum Exploration and Development, vol. 30, no. 6, pp. 32-34, 2003.

[8] X. Q. Si, B. Yuan, H. J. Guo, X. U. Yang, C. H. E. N. Nenggui, and P. E. N. G. Bo, "Reservoir characteristics and main controlling factors of cretaceous Qingshuihe formation in the southern margin of Junggar Basin," Xinjiang Petroleum Geology, vol. 41, no. 2, pp. 38-45, 2020.

[9] J. Yao, C. Q. Huang, W. Z. Liu, Y. Zhang, Q. Zeng, and X. Yan, "Key mechanical problems in the development of deep oil and gas reservoirs," SCIENTIA SINICA Physica, Mechanica \& Astronomica, vol. 48, 2018.

[10] J. C. Guo, Z. H. Hao, and Q. L. Lu, "Research progress in key mechanical theories of deep shale network fracturing," Natural Gas Industry, vol. 41, no. 1, pp. 102-117, 2021.

[11] K. Oladoyin, F. Gabriella, and S. István, "Formation susceptibility to wellbore instability and sand production in the Pannonian Basin, Hungary," in The 52nd US Rock Mechanics / Geomechanics SymposiumAmerican Rock Mechanics Association.

[12] M. J. Economides and K. G. Nolte, Reservoir Stimulation, John Wiley \& Sons, Ltd., Third edition, 2000.

[13] L. Y. Zhang, X. B. Mao, and A. H. Lu, "Experimental study on the mechanical properties of rocks at high temperature," Science in China Series E: Technological Sciences, vol. 52, no. 3, pp. 641-646, 2009.

[14] Q. Sun, Z. Z. Zhang, L. Xue, and S. Y. Zhu, "Physico-mechanical properties variation of rock with phase transformation under high temperature," Chinese Journal of Rock Mechanics and Engineering, vol. 32, no. 5, pp. 935-942, 2013.

[15] A. S. Chiarelli, J. F. Shao, and N. Hoteit, "Modeling of elastoplastic damage behavior of a claystone," International Journal of Plasticity, vol. 19, pp. 23-45, 2003.

[16] H. Tian, T. Kempka, S. Yu, and M. Ziegler, "Mechanical properties of sandstones exposed to high temperature," Rock Mechanics and Rock Engineering, vol. 49, no. 1, pp. 321-327, 2016.

[17] Z. J. Wan, Y. S. Zhao, F. K. Dong, Z. Feng, N. Zhang, and J. Wu, "Experimental study on mechanical characteristics of granite under high temperatures and triaxial stresses," Chinese Journal of Rock Mechanics and Engineering, vol. 27, no. 1, pp. 72-77, 2008.

[18] H. Deng, M. Zhang, T. H. Deng, and Q. Zhang, "A triaxial compression test of tight quartz sandstone under high temperature and high confining pressure," Oil \& Gas Geology, vol. 38, no. 6, pp. 1172-1179, 2017.

[19] W. G. P. Kumari, P. G. Ranjith, M. S. A. Perera et al., "Mechanical behaviour of Australian Strathbogie granite under in-situ stress and temperature conditions: an application to geothermal energy extraction," Geothermics, vol. 65, pp. 44-59, 2017.

[20] Q. C. Zhou, H. B. Li, C. H. Yang, H. S. MA, and L. J. CHEN, "Experimental study on thermo-mechanical and hydromechanical coupling of sandstone for west route of southto-north water transfer project," Chinese Journal of Rock Mechanics and Engineering, vol. 24, no. 20, pp. 3639-3645, 2005.

[21] L. H. Pan, S. C. Zhang, L. J. Cheng et al., "Experimental study on mechanical property of carbonate under the effect of confining pressure and pore pressure," Journal of Xi'an Shiyou University, vol. 29, no. 5, pp. 17-20, 2014. 
[22] S. M. Liao, C. Y. She, Y. Sang, and J. C. Guo, Theory and Technology of Fracture Network Fracturing in Tight Gas Reservoir, Petroleum Industry Press, 2016.

[23] J. Xie, H. M. Wu, Y. S. Lou, and X. P. Zhai, "Fracture pressure prediction model of high temperature and high pressure formation in deep water area of the South China Sea," Fault-Block Oil and Gas Field, vol. 28, no. 3, pp. 378-382, 2021.

[24] K. H. S. M. Sampath, M. S. A. Perera, and P. G. Ranjith, “Theoretical overview of hydraulic fracturing break-down pressure," Journal of Natural Gas Science and Engineering, vol. 58, pp. 251-265, 2018.

[25] M. K. Hubbert and D. G. Willis, "Mechanics of hydraulic fracturing," AIME Petroleum Transactions, vol. 210, no. 1, pp. 153-168, 1957.

[26] B. Haimson and C. Fairhurs, "Initiation and extension of hydraulic fractures in rocks," Society of Petroleum Engineers Journal, vol. 7, no. 3, pp. 310-318, 1967.

[27] B. Eaton, "Fracture gradient prediction and its application in oilfield operations," Journal of Petroleum Technology, vol. 21, no. 10, pp. 1353-1360, 1969.

[28] R. D. Stephen, "Prediction of fracture pressures for wildcat wells," Journal of Petroleum Technology, vol. 34, no. 4, pp. 863-872, 1982.

[29] R. A. Anderson, D. S. Ingram, and A. M. Zanier, "Determining fracture pressure gradients from well logs," Journal of Petroleum Technology, vol. 25, no. 11, pp. 1259-1268, 1973.

[30] R. Z. Huang, "Discussion on prediction model of formation fracture pressure," Journal of East China Petroleum Institute, vol. 4, pp. 335-347, 1984.

[31] T. Ito and K. Hayashi, "Physical background to the breakdown pressure in hydraulic fracturing tectonic stress measurements," International Journal of Rock Mechanics and Mining Sciences \& Geomechanics Abstracts, vol. 28, no. 4, pp. 285293, 1991.

[32] T. K. Guo, S. C. Zhang, W. L. Liu, and L. Wenxu, "Initiation pressure of multi-stage fracking for perforated horizontal wells of shale gas reservoirs," Natural Gas Industry, vol. 33, no. 12, pp. 87-93, 2013.

[33] Y. Fan, Y. L. Zhao, Z. M. Zhu, C. L. Zhou, and X. S. Zhang, "Theoretical study of break down pressures and fracture initiation angles based on model containing wellbore and perforations," Journal of Central South University (Natural Science), vol. 50, no. 3, pp. 669-679, 2019.

[34] B. Lecampion, "Modeling size effects associated with tensile fracture initiation from a wellbore," International Journal of Rock Mechanics and Mining Sciences, vol. 56, pp. 67-76, 2012.

[35] P. Cornetti, N. Pugno, A. Carpinteri, and D. Taylor, "Finite fracture mechanics: a coupled stress and energy failure criterion," Engineering Fracture Mechanics, vol. 73, no. 14, pp. 2021-2033, 2006.

[36] X. R. Luo, L. J. Liu, and X. Y. Li, “Overpressure distribution and pressuring mechanism on the southern margin of the Junggar Basin, northwestern China," Chinese Science Bulletin, vol. 51, no. 19, pp. 2383-2390, 2006.

[37] Y. X. Liu, H. Y. Zhou, J. C. Guo, and J. Wang, "Mechanical characteristics and influencing factors of shallow igneous rocks in Junggar Basin," IOP Conference Series: Earth and Environmental Science, vol. 861, 2021.

[38] B. Yuan, X. M. Dong, X. T. Guan et al., "Analysis of characteristics of tight sandstone reservoir with porous-fissure dual medium in Toutunhe formation of Sikeshu sag," Acta Scien- tiarum Naturalium Universitatis Pekinensis (Natural Science), vol. 56, no. 3, pp. 449-459, 2020.

[39] R. Ulusay, The ISRM Suggested Methods for Rock Characterization, Testing and Monitoring: 2007-2014, Springer International Publishing, 2015.

[40] S. G. Li, J. G. Deng, B. H. Yu, and L. J. Yu, "Formation fracture pressure calculation in high temperatures wells," Chinese journal of rock mechanics and engineering, vol. 24, pp. 5669-5673, 2005.

[41] J. C. Guo, S. G. He, Y. Deng, and Z. Zhao, "New stress and initiation model of hydraulic fracturing based on nonlinear constitutive equation," Journal of Natural Gas Science and Engineering, vol. 27, pp. 666-675, 2015.

[42] P. Zhang, B. Mishra, and K. A. Heasley, "Experimental investigation on the influence of high pressure and high temperature on the mechanical properties of deep reservoir rocks," Rock Mechanics and Rock Engineering, vol. 48, no. 6, pp. 2197-2211, 2015. 